\title{
A STUDY OF POSTOPERATIVE LARYNGOSPASM IN PAEDIATRIC AGE GROUP
}

\author{
Ravi Nagaprasad Yerramilli1 ${ }^{1}$ Sunil Kumar Cherukuri²
}

${ }^{1}$ Assistant Professor, Department of Anaesthesiology, Niloufer Hospital for Women and Children, Osmania Medical College, Hyderabad, Telangana.

${ }^{2}$ Assistant Professor, Department of Anaesthesiology, Niloufer Hospital for Women and Children, Osmania Medical College, Hyderabad, Telangana.

\section{ABSTRACT}

\section{BACKGROUND}

Postoperative laryngospasm is an anaesthetic emergency that is still responsible for significant morbidity and mortality in paediatric patients. It is relatively a frequent complication and requires prompt recognition and early correction by resorting to different manoeuvres and medications.

\section{METHODS}

A study had been done to know the incidence of postoperative laryngospasm in our institute in the year 2014. The reported cases of laryngospasm were managed by a protocol set in algorithm and the efficacy of each step in the management algorithm was evaluated.

\section{RESULTS}

The incidence of Postoperative Laryngospasm in our study was found to be 9.32/1000, which was similar to that published in the literature. We also found that majority of laryngospasms can be managed by simple manoeuvres like Chin lift, Jaw thrust, Intermittent Positive Pressure Ventilation $\{$ IPPV $\}$ or Continuous Positive Airway Pressure $\{$ CPAP\} with $100 \%$ 02. An Intravenous bolus dose of Propofol was found to be effective in the treatment of postoperative laryngospasm.

\section{CONCLUSION}

Laryngospasm even though an alarming postoperative complication can be managed effectively by simple manoeuvres and some pharmacological intervention if it is tackled by a set protocol based algorithm.

\section{KEYWORDS}

Laryngospasm, Postoperative Complication, Hypoxia, Bradycardia, Management Plan.

HOW TO CITE THIS ARTICLE: Yerramilli RN, Cherukuri SK. A study of postoperative laryngospasm in paediatric age group. J. Evolution Med. Dent. Sci. 2016;5(27):1391-1393, DOI: 10.14260/jemds/2016/328

\section{INTRODUCTION}

Laryngospasm is a protective reflex closure of glottis as a result of abnormal stimulus. ${ }^{1}$ It is more common in paediatric age group. ${ }^{2}$ Postoperative laryngospasm can rapidly result in hypoxia and bradycardia. It has to be managed promptly and efficiently by a clear management plan in order to reestablish oxygenation. A prospective study had been done in our institute to determine the incidence of postoperative laryngospasm and to know the efficacy of treatment protocols in the management of laryngospasm.

\section{AIM OF THE STUDY}

The purpose of this study is to know the incidence of postoperative laryngospasm in paediatric age group from 1 day to 10 yrs. in the year 2014 and to evaluate the efficacy of different treatment procedures in the management of laryngospasm.

\section{MATERIALS AND METHODS}

The study was conducted in our hospital from Jan. 2014 to Dec. 2014. All the children of age 1 day to 10 yrs. who developed laryngospasm at the time of recovery from anaesthesia in the operation theatre were noted during that period.

Financial or Other, Competing Interest: None.

Submission 16-02-2016, Peer Review 11-03-2016,

Acceptance 17-03-2016, Published 04-04-2016.

Corresponding Author:

Dr. Ravi Nagaprasad Yerramilli,

B/4 Madhura Nagar, S. R. Nagar (P.O),

Hydearbad-500038.

E-mail: yerramilli.rnp@gmail.com

DOI: $10.14260 /$ jemds $/ 2016 / 328$
All these patients were managed by an Assistant Professor and a resident of Department of Anaesthesia by a set protocol as suggested by Hampson-Evans D et al. ${ }^{3}$ The protocol for the management of postoperative laryngospasm followed in our institution was as follows: \{guidelines from Orliaguet et al. ${ }^{2}$ and D. Hampson-Evans et al. ${ }^{3}$

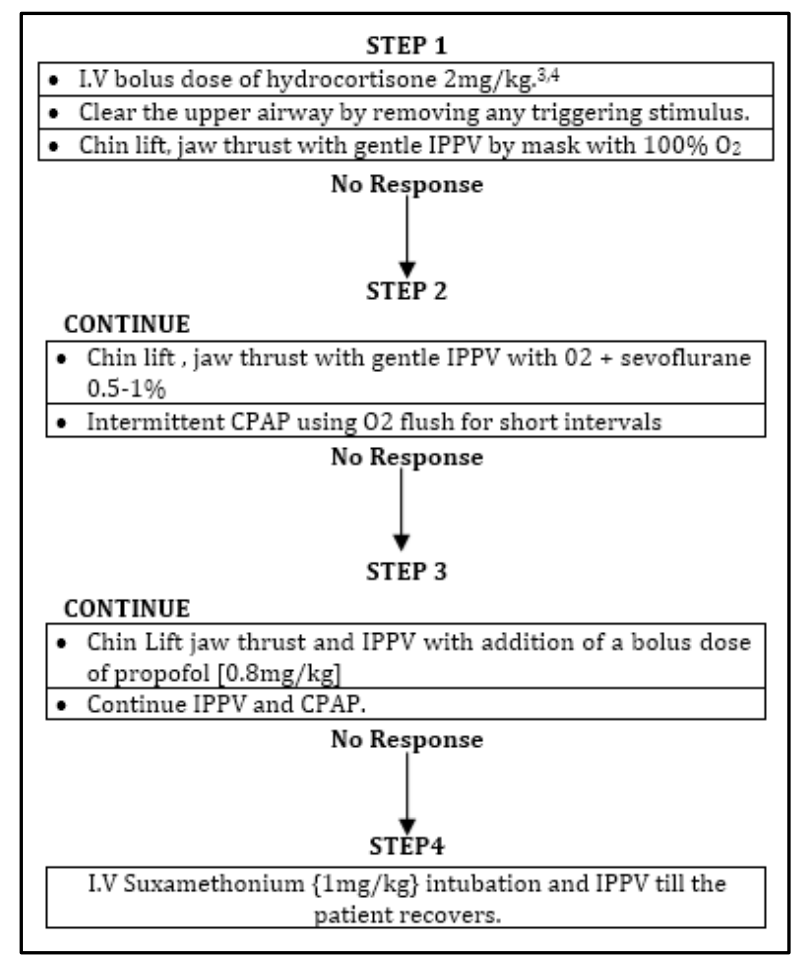


IV Hydrocortisone $2 \mathrm{mg} / \mathrm{kg}$ is given to all patients in step 1 [As an hospital protocol] in order to avoid laryngeal congestion and oedema during postoperative period. 4,5 Once respiratory rhythm is established sevoflurane is cut off and patient is kept on Hudson's mask with 40\% 02 and monitored in postoperative ward. The number of cases which can be treated successfully at each step were studied.

\section{Exclusion Criteria}

Syndromic babies with anticipatory difficult airways, ASA Grade 3 and Grade 4 children and premature babies were excluded from the study group as their perioperative management is different and may require postoperative ventilatory support in ICU.

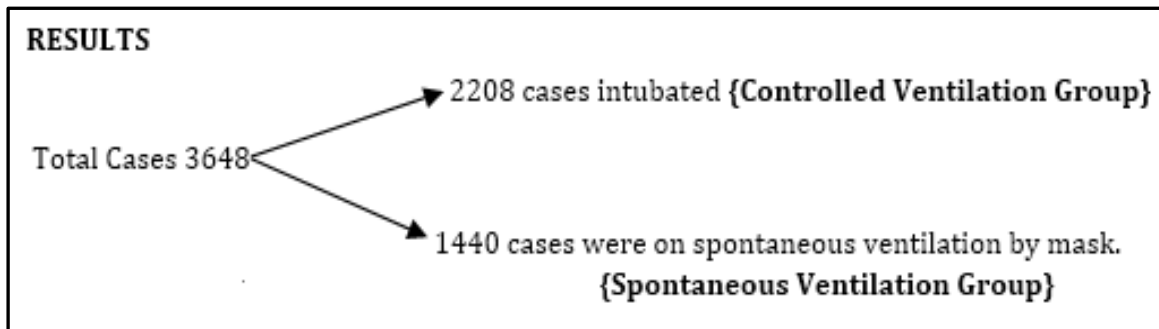

Total number of surgeries done under general anaesthesia from January 2014 to December 2014 were 3648 \{2208 cases were given Controlled Ventilation Anaesthesia and 1440 cases were anaesthetized on spontaneous ventilation by mask.\}

Total number of cases which developed postoperative laryngospasm was 34; 24 cases were from controlled ventilation group and 10 cases from spontaneous ventilation group.

Table 1 shows the demographic and age distribution of cases, which had postoperative laryngospasm; 35.3\% $\{12 / 34\}$ of cases occurred during the age group of 1 month to 1 year (During infancy).

Table 2 shows the treatment response of 34 cases to the Management Algorithm; 33/34 cases were managed by STEP $1,2,3$. Only $2.9 \%\{1$ case $\}$ required the use of muscle relaxant suxamethonium. The case was intubated, ventilated and later extubated in PICU; 47.05\% \{16/34\} cases were given IV bolus propofol in order to relieve the laryngospasm (Step 3).

Table 3 shows surgeries performed in the cases, which developed postoperative laryngospasm.

\begin{tabular}{|c|c|c|c|c|}
\hline Age & $\begin{array}{c}\text { Total } \\
\text { No. } \\
\text { Cases }\end{array}$ & $\begin{array}{c}\text { No. } \\
\text { Males }\end{array}$ & $\begin{array}{c}\text { No. } \\
\text { Females }\end{array}$ & $\begin{array}{c}\% \\
\text { Distribution }\end{array}$ \\
\hline 1 day - 1 mon & 6 & 4 & 2 & $17.64 \%$ \\
\hline 1 mon - 1 yr. & 12 & 6 & 6 & $35.30 \%$ \\
\hline 1 yr. - 5 yrs. & 7 & 4 & 3 & $20.60 \%$ \\
\hline 5 yrs. - 10 yrs. & 9 & 5 & 4 & $26.47 \%$ \\
\hline \multicolumn{4}{|c|}{ Table 1: Age \& Sex Distribution of Children } \\
who developed Laryngospasm \\
\hline
\end{tabular}

\begin{tabular}{|c|c|c|c|c|c|}
\hline & & \multicolumn{4}{|c|}{ No. Cases Responding to Treatment } \\
\hline $\begin{array}{l}\text { Sl. } \\
\text { No. }\end{array}$ & Age & $\begin{array}{c}\text { STEP } \\
1\end{array}$ & $\begin{array}{c}\text { STEP } \\
2\end{array}$ & $\begin{array}{c}\text { STEP } \\
3\end{array}$ & $\begin{array}{c}\text { STEP } \\
4\end{array}$ \\
\hline 1 & 1 day-1 month & 2 & 1 & 3 & - \\
\hline 2 & 1 mon-1 yr. & 2 & 5 & 5 & - \\
\hline 3 & 1 yr. -5 yr. & 2 & 2 & 3 & - \\
\hline 4 & $5-10$ yrs. & 1 & 2 & 5 & 1 \\
\hline & Total & 7 & 10 & 16 & $\mathbf{1}$ \\
\hline 5 & $\%$ & $20.6 \%$ & $29.4 \%$ & $47.0 \%$ & $2.9 \%$ \\
\hline & $\begin{array}{c}\text { Table 2: } N \\
\text { Laryng }\end{array}$ & $m \&$ & $\begin{array}{l}\text { Post } \\
\text { ir Res }\end{array}$ & $\begin{array}{l}\text { ative } \\
\text { se }\end{array}$ & \\
\hline
\end{tabular}

\begin{tabular}{|c|c|c|}
\hline Sl. No. & Surgery & No. Cases \\
\hline 1 & Herniorrhaphy & 13 \\
\hline 2 & Pyeloplasty & 3 \\
\hline 3 & Pyloromyotomy operation & 2 \\
\hline 4 & Colostomy making & 2 \\
\hline 5 & Circumcision & 9 \\
\hline 6 & Cystoscopy \& Fulguration & 4 \\
\hline 7 & Meningomyelocele surgery & 1 \\
\hline \multicolumn{3}{|c|}{ Table 3: Shows Surgical Procedures in Cases } \\
that had Laryngospasm \\
\hline
\end{tabular}

\section{OBSERVATION}

34 out of 3648 cases developed postoperative laryngospasm in the year 2014 in our institute. The incidence was found to be $9.32 / 1000$.

12 out of 34 cases $\{35.29 \%\}$ fall under the age group of 1 month to 1 year. The incidence is maximum between the age group from 1 month to 1 year; $16 / 34\{47.05 \%$ of patients were relieved from laryngospasm in step 3 using IV Propofol bolus dose with chin lift jaw thrust and gentle IPPV with $100 \% \quad \mathrm{O}_{2}$. Maximum number of patients were successfully treated in the step 3 of management protocol. All the patients except 1 child responded to the treatment of steps 1,2 and 3.

Only 1 child was given suxamethonium and intubated. The child was ventilated and later extubated in PICU. Majority of postoperative laryngospasm can successfully be managed by chin lift, Jaw thrust with gentle IPPV/CPAP with 100\% 02 along with IV propofol. Usage of muscle relaxant suxamethonium was very rare.

\section{DISCUSSION}

The incidence of postoperative laryngospasm found in our study is $9.3 / 1000$. Gilles A. Orlaguet reported the incidence to be as high as $17 / 1000$ in children when compared to $8.7 / 1000$ in general population. Incidence of laryngospasm was reported to be as high as 20/1000 in high risk surgeries like otolaryngeal surgeries. ${ }^{2}$

Olsson et al. has done an 11-year prospective study on the incidence of postoperative laryngospasms in children. In his extensive prospective study in 1,36,929 patients he found the incidence to be $7.9-8.7 / 1000.6$ In our study we found the incidence to be $9.3 / 1000$, which is nearly similar to their incidence rate. Dilip Pawar has reported that incidence of postoperative laryngospasm is three times higher in infants than in the older children. ${ }^{7}$ In our studies, we also found $35.30 \%$ of patients who developed laryngospasm fall in the age group of 1 month to $1 \mathrm{yr}$. (Infancy). 
Mammie et al. reported $17 / 1000$ cases in their study. They also found that incidence of laryngospasm is high in otolaryngology surgery. ${ }^{8}$ Achir Ahmed Al-Alami et al. in their studies published in The Journal of Anaesthesiology 2009 reported a wider range of incidence. They found incidence of postoperative laryngospasm is $0.4-14 \%{ }^{1}$

Effective management of laryngospasm requires appropriate diagnosis followed by prompt and aggressive treatment. Many methods and techniques of airway manipulation have been proposed. These interventions include removal of irritant stimulant, chin lift, jaw thrust, positive pressure ventilation and sometimes CPAP with face mask. ${ }^{2,3}$

Less commonly used airway manoeuvre like pressure in the "Laryngeal notch" and digital elevation of the tongue have also been practiced.2,9,10 Recently, a new technique of gentle chest compression has been proposed as an alternative to standard practice for relief of laryngospasm.2,3

In our study, we performed steps like chin lift, jaw thrust with gentle IPPV. CPAP was applied only if child was not responding to IPPV. Bergoyne et al. also in their study had similar management protocol.11 but it also covered anaesthesia for diagnostic and therapeutic procedure outside the theatre setting. Their study also evaluated the interventions used in the management of laryngospasm.

IV Propofol $0.8 \mathrm{mg} / \mathrm{kg}$ has been effective in the management of laryngospasm. Gilles A. Orlaguet et al. also found that IV Propofol in the dose of $0.8 \mathrm{mg} / \mathrm{kg}$ is superior to other drugs in the treatment of postoperative laryngospasm. ${ }^{2}$ Dilip Pawar also advocated the use of Propofol $(0.8 \mathrm{mg} / \mathrm{kg})$ in the management of laryngospasm. ${ }^{6}$

Usage of Lidocaine (Plain) in the management of laryngospasm has been controversial. It was found to be effective in the prevention of laryngospasm in palate surgeries. ${ }^{12}$ But Gilles A. Orlaguet et al. recommended omitting the IV Lidocaine in the treatment algorithm of laryngospasm, although some authors have included it. ${ }^{2}$ Other drugs like Magnesium, Doxapram, Diazepam and Nitroglycerin have been used, but their efficacy has not been established.2,3

We found addition of small bolus dose, IV dose of propofol improved IPPV and saturation of majority of cases.

Orliguet et al. has also strongly recommended the integration of simulation based training for paediatric airway management including for management of laryngospasm. ${ }^{2}$ We also feel that a management algorithm, which is suitable to the institute should be framed and proper training in the management of laryngospasm would improve the outcome.

\section{CONCLUSION}

Postoperative laryngospasm is one of the most important complications in the paediatric patients and its management involves correct and prompt execution of set protocol procedures to avoid morbidity. A protocol based algorithm consisting of simple steps like chin lift, jaw thrust, gentle IPPV with $100 \%$ combined with an IV bolus of Propofol can relieve majority of postoperative laryngospasm. Usage of suxamethonium and intubation is rarely required. As proposed by some authors like Gilles A. Orlioguet et al. we also feel that simulation based training in the management of laryngospasm will be very helpful in tackling this postoperative complication much more efficiently.

\section{REFERENCES}

1. Al-Alami AA, Zostos MM, Baraka AS. Paediatric laryngospasm: prevention and treatment. Curr Opin Anaesthesiol 2009;22(3):388-95.

2. Orliaguet GA, Gall O, Savaldelli GL, et al. Case scenario: perianaesthetic management of laryngospasm in children. Anaesthesiology 2012;116(2):458-71.

3. Hampson-Evans D, Morgan P, Ferrar M. Paediatric laryngospasm. Paediatr Anaesth 2008;18:303-7.

4. Pramod Patra, Debashish Nayak. Dexamethasone as prophylaxisis! is it effective in reducing postoperative extubation blues in paediatric age group? A retrospective review of 331 patients. Indian Journal of Anaesthesia 2008;52(3):305-310.

5. François B, Bellissant E, Gissot V, et al. 12-hourpretreatment with methylprednisolone versus placebo for prevention of postextubation laryngeal oedema: a randomised, double-blind trial. Lancet 2007;369(9567):1083-1089.

6. Olsson GL, Hallen B. Laryngospasm during anaesthesia. A computer aided incidence study in 136,929 patients. Acta Anaesthesiol Scand 1984;28(5):557-67.

7. Dilip Pawar. Common postoperative complications in children. Indian Journal of Anaesthesiology 2012;56(5):496-01.

8. Mamie C, Habre W, Delhumeau C, et al. Incidence and risk factors of perioperative respiratory adverse effects in children undergoing elective surgery. Paediatr Anaesth 2004;14(3):218-24.

9. Gil Gaver, Robert WM Walker. Laryngospasm in anaesthesia. Continuing Education In Anaesthesia, Critical Care And Pain 2013.

10. D'souza N, Garg R. Perioperative laryngospasm-review of literature. Internet Journal of Anaesthesiology 2008;20(1):1-8.

11. Bergoyne LL, Angelescau DL. Intervention steps for treating laryngospam in paediatric patient. Paediatr Anaesth 2008;18(4):297-02.

12. Roy WL, Lerman J. Laryngospasm in paediatric anaesthesia. Can J Anaesth 1988;35(1):93-98. 